\title{
Penerapan Filter Kalman Dalam Perbaikan Hasil Prediksi Return Harga Minyak Mentah Dunia dengan Model ARIMA
}

\author{
Yoga Faisal Aminnudin, Erna Apriliani, dan Nuri Wahyuningsih \\ Departemen Matematika, Fakultas Matematika Komputasi dan Sains Data, Institut Teknologi Sepuluh Nopember \\ (ITS) \\ e-mail:nuri@matematika.its.ac.id
}

\begin{abstract}
Abstrak-Peramalan terhadap harga komoditas minyak mentah dunia merupakan salah satu studi yang dilakukan untuk mengantisipasi harga periode mendatang dari komoditas minyak guna menjaga kestabilan ekonomi. Pada penelitian ini digunakan Autoregressive Integrated Moving Average (ARIMA) untuk merumuskan model peramalan return harga komoditas minyak mentah. Pada ARIMA didapatkan model yang sesuai yaitu ARIMA ([14],0,[14]) dengan nilai Mean Absolute Percentage Error (MAPE) yang masih sangat besar yaitu 217, 2554\%.Setelah didapatkan model yang sesuai dilakukan estimasi terhadap parameter dan perbaikan error pada model tersebut dengan Filter Kalman. Hasil akhir menunjukkan bahwa model peramalan pada return harga minyak terbaik adalah dari hasil perbaikan error menggunakan Filter Kalman yang memiliki nilai MAPE terkecil yaitu $3,6947 \%$ sehingga hasil ramalan lebih akurat.
\end{abstract}

Kata Kunci-ARIMA, Estimasi Parameter, Filter Kalman, Perbaikan Error.

\section{PENDAHULUAN}

$\mathrm{D}$ ALAM rentang waktu Januari sampai dengan Juli 2014, harga minyak dunia versi WTI (West Texas Intermediate) rata-rata selalu bertengger di atas 100 USD per barel. Namun dalam periode enam bulan berikutnya, harga minyak turun secara tajam ke level 44 USD per barel saja. Perlu kita ketahui bersama, referensi WTI dari Amerika ini adalah salah satu rujukan harga minyak mentah di seluruh dunia, termasuk harga minyak mentah dari perut bumi Indonesia www.eia.doe.gov [1]. Dari fakta tersebut kita ketahui bahwa harga minya mentah duni sangat fluktuatif. Fluktuasi harga minyak mentah dunia memiliki dampak yang sangat signifikan di dunia, khususnya Indonesia. Hal ini tak lepas dari ketergantungan Indonesia terhadap sumber energi yang bersifat non-renewable tersebut. Akibatnya, seringkali pemerintah mengambil kebijakan menaikkan harga komoditi yang tegantung pada kenaikan harga minyak sebagai bahan baku Bahan Bakar Berminyak (BBM) di Indonesia tersebut. Dalam perspektif makroekonomi, perubahan harga minyak mentah sebagai bahan baku utama BBM akan cenderung diikuti oleh perubahan volume produksi berbagai kelompok industri maupun perusahaan, serta bank pusat selalu memperhatikan pergerakan harga minyak dunia. Besaran pergerakan harga minyak secara drastis inilah yang perlu diestimasi agar dapat mempersiapkan kebijakan terhadap pergerakan harga minyak mentah kedepannya. Oleh karena itu, perlu dilakukan pengukuran statistik untuk volatilitas harga minyak selama periode tertentu.

Robert Engle [2] pada tahun 1982 mengembangkan suatu model untuk mengestimasi perilaku volatilitas pada data yang mengalami time varying variance (heteroskedastisitas) dan volatility clustering yang disebut dengan Autoregres sive Conditional Heteroscedastic (ARCH). Namun model ARCH kurang efisien digunakan karena pada saat mengestimasi data seringkali diperlukan pendugaan parameter yang cukup banyak (membutuhkan lag yang panjang) sehingga dikembangkan model oleh Tim Bollerslev dan Taylor pada tahun 1986 yang bernama Generalized ARCH (GARCH) [3]. Oleh karena itu, pada penelitian ini dilakukan estimasi volatilitas dengan menggunakan model GARCH. Selanjutnya model GARCH yang didapat akan digunakan untuk melakukan prediksi dan penggunaan Filter Kalman yang terdiri dari suatu himpunan atas persamaan matematika akan memberikan sebuah solusi komputasi yang efisien dari metode kuadrat terkecil. Sehingga nantinya metode Filter Kalman ini dapat terterapkan dalam perbaikan prediksi volatilitas harga minyak dunia.

\section{METODOLOGI PENELITIAN}

\section{A. Sumber Data}

Data yang digunakan dalam penelitian adalah data sekunder dari return harga minyak mentah dunia jenis West Texas Intermediate yang diperoleh dari www.eia.doe.gov mulai tanggal 1 Maret 2017 hingga 17 November 2017. Data dibagi menjadi dua bagian, yaitu data in sample dan data out sample. Data in sample digunakan untuk merumuskan model ARIMA serta diuji adanya unsurheteroskedastisitas dan data out sample untuk mengetahui ketepatan model. Dalam penelitian ini digunakan data in sample untuk merumuskan model diambil mulai tanggal 1 Maret 2017 hingga 8 September 2017 (sebanyak 134 data), sedangkan data out sample diambil mulai 11 September 2017 hingga 17 November 2017.

\section{B. Analisis Time Series}

Langkah pertama adalah melakukan uji stasioneritas dengan menggunakan plot Box-Cox dan time series. Setelah data sudah stasioner dalam varian maupun mean, dibuat plot ACF dan PACF untuk menentukan orde model ARIMA. Setelah didapatkan dugaan model sementara, akan dilakukan uji signifikansi parameter, residual bersifat white noise dan berdistribusi normal, serta mempunyai nilai AIC dan SBC terkecil. 
Tabel 1 .

Model ARIMA Terbaik pada Data Return Harga Minyak Mentah dengan In Sample 231

\begin{tabular}{ccc}
\hline \hline Data & Model ARIMA & $\begin{array}{c}\text { MAPE } \\
\text { Dalam (\%) }\end{array}$ \\
\hline $\begin{array}{c}\text { Harga Minyak } \\
\begin{array}{c}\text { Mentah Jenis } \\
\text { WTI }\end{array}\end{array}$ & ARIMA & 217,2554 \\
$([14], 0,[14])$ & \\
\hline \hline
\end{tabular}

Setelah mendapatkan model ARIMA, kemudian dilakukan uji adanya unsur heteroskedastisitas. Pada model ARIMA yang masih terdapat unsur heterokedastisitas akan diperlukan model varian ARCH dan GARCH untuk menyelesaikan masalah volatilitas di dalam heterokedastisitas. Pada model ARIMA atau GARCH yang sesuai pada harga minyak mentah akan diterapkan Filter Kalman untuk mengestimasi parameter dan memperbaiki error pada model. Langkah terakhir adalah melakukan validasi dengan membandingkan nilai MAPE hasil peramalan model ARIMA yang parameter dan errornya diestimasi menggunakan Filter Kalman dengan hasil peramalan ARIMA yang diestimasi menggunakan metode Least Square.

\section{HASIL DAN PEMBAHASAN}

\section{A. Pemodelan ARIMA}

Langkah pertama dalam merumuskan model ARIMA adalah melakukan uji stasioneritas data terhadap varian dan mean. Data yang akan diuji adalah data harga minyak mentah jenis WTI dengan in sample sebanyak 134. Untuk melihat kestasioneran data terhadap varian dapat menggunakan plot Box-Cox dan data time series. Apabila data tersebut sudah stasioner terhadap varian (rounded value $=1$ ) maka tidak perlu dilakukan transformasi, namun apabila belum stasioner (rounded value $\neq 1$ ) terhadap varian harus dilakukan proses transformasi sampai data stasioner (rounded value $=1$ ). Sedangkan untuk melihat kestasioneran terhadap mean dapat dilihat dari plot tren anilisis data pada software Minitab, apabila data menunjukkan pola yang teratur serta tidak terjadi fluktuasi yang signifikan. Untuk hasil dari adanya proses Transformasi Box-Cox dan differencing ditunjukkan pada masing-masing Gambar 1 dan Gambar 2.

Setelah data stasioner terhadap varian dan mean, dilakukan plot ACF dan PACF untuk mendapatkan model sementara. Pada data return harga minyak jenis WTI, plot ACF keluar pada lag ke-14 seperti pada Gambar 3, sedangkan plot PACF keluar pada lag ke-14 seperti pada Gambar 4. Sehingga pendugaan model sementara pada data returnharga minyak jenis WTI adalah ARIMA ([14], 0, [14]).

Selanjutnya dilakukan estimasi parameter dan uji signifikansi, uji residual white noise, serta uji residual berdistribusi normal. Apabila model sementara belum memenuhi semua uji tersebut maka perlu dilakukan overfitting. Pada saat melakukan proses overfitting ditambahkan 2 model yaitu ARIMA ([14], 0,0) dan ARIMA $(0,0,[14])$. Model ARIMA terbaik diperoleh dengan membandingkan nilai AIC dan SBC yang terkecil. Langkah yang sama dilakukan untuk pendugaan model ARIMA.

Tabel 1 menunjukkan hasil model ARIMA terbaik dari data return harga minyak jenis WTI, yang juga telah memenuhi uji signifikansi, asumsi residual bersifat white noise dan residual berdistribusi normal.
Untuk hasil simulasi perbandingan Data Faktual dengan hasil permalan ARIMA dapat dilihat pada Gambar 5.

Sehingga model ARIMA terbaik untuk meramalkan harga minyak periode mendatang dapat ditulis:

$X_{t}=\emptyset_{14} X_{t-14}+\alpha_{t}-\theta_{14} \alpha_{t-14}$

$X_{t}=0,986 X_{t-14}+\alpha_{t}+0,884 \alpha_{t-14}$

dimana:

$X_{t}=Y_{t}^{1,5}=Y_{t}^{3 / 2}$

sehingga diperoleh persamaan dalam $Y_{t}$ :

$Y_{t}=\left(0,986\left(Y_{t-14}\right)^{3 / 2}+\alpha_{t}+0,884 \alpha_{t-14}\right)^{\frac{2}{3}}$

dengan:

$\theta_{1,2, \ldots, q}:$ koefisien orde ke- $1,2, \ldots, q$

$a_{t} \quad$ : nilai kesalahan pada waktu ke- $t$

$X_{t} \quad$ : besarnya pengamatan pada waktu ke- $t\left(X_{t}\right.$ merupakan bentuktransformasi dari $Y_{t}$ )

$Y_{t} \quad$ : besarnya pengamatan pada waktu ke- $t$

Selanjutnya dilakukan uji statistic Ljung-Box terhadap residual kuadrat model untuk mengatahui ada atau tidaknya unsurheteroskedastisitas dalam model.

Hipotes is:

$H_{0}$ : Tidak ada unsurheterokedastisitas (homokedastisitas)

$H_{1}$ : Terdapat unsurheterokedastisitas

Dengan nilai statistic uji $L B=-0,078$ dan nilai $\chi_{(0.05 ; 12)}^{2}=5,2$ maka $L B<\chi^{2}{ }_{(0.05 ; 12)}$ yang menyebabkan $H_{0}$ diterima artinya tidak terdapat unsur heteroskedastisitas. Oleh karena itu, cukup digunakan model terbaik ARIMA.

\section{B. Estimasi Parameter Menggunakan Filter Kalman}

Setelah memperoleh model ARIMA yang sesuai, Filter Kalman diterapkan untuk mengestimasi parameter model ARIMA. Parameter dan state yang akan diestimasi adalah $\emptyset_{t}$ dan $\theta_{t}$ serta mengestimasi nilai $X_{t}$. Nilai koefisien diestimasi menggunakan Filter Kalman berdasarkan model ARIMA harga minyak mentah. Berikut ini penerapan Filter Kalman pada harga minyak mentah:

Persamaan model ARIMA pada harga minyak:

$$
X_{t}=0,986\left(Y_{t-14}\right)^{3 / 2}+\alpha_{t}+0,884 \alpha_{t-14}
$$

dengan $x_{t}=\left[\begin{array}{lll}\emptyset_{t} & \theta_{t} & X_{t}\end{array}\right]^{T}$ dan $H=\left[\begin{array}{lll}0 & 0 & 1\end{array}\right]$

Algoritma Filter Kalman yang digunakan dalam penelitian ini adalah sebagaiberikut:

Model system [4]:

$\left[\begin{array}{c}\emptyset_{14} \\ \theta_{14} \\ X_{t}\end{array}\right]_{t+1}=\left[\begin{array}{ccc}1 & 0 & 1 \\ 0 & 1 & 0 \\ X_{t-14} & -\alpha_{t-14} & 0\end{array}\right]\left[\begin{array}{c}\emptyset_{14} \\ \theta_{14} \\ X_{t}\end{array}\right]_{t}+w_{t}$

Model pengukuran[6]:

$z_{t}=X_{t}=\left[\begin{array}{lll}0 & 0 & 1\end{array}\right]\left[\begin{array}{c}\emptyset_{14} \\ \theta_{14} \\ X_{t}\end{array}\right]_{t}$

Selanjutnya tahap inisialisasi, dengan menentukan nilai awal sebagaiberikut:

$R=10^{-7}, Q=10^{-6}$

$\hat{x}_{0}=\left[\begin{array}{c}0,98 \\ -0,88 \\ -0,00019\end{array}\right], P_{0}=\left[\begin{array}{lll}1 & 0 & 0 \\ 0 & 1 & 0 \\ 0 & 0 & 1\end{array}\right]$

Tahap prediksi [4]:

$\hat{x}_{\bar{t}+1}=A_{t} \hat{x}_{t}$

$P_{\bar{t}+1}=A_{t} P_{t} A_{t}^{T}+G Q_{t} G^{T}$

Tahap koreksi [4]:

$K_{t+1}=P_{\bar{t}+1} H_{t+1}^{T}\left(H_{t+1} P_{\bar{t}+1} H_{t+1}^{T}+R_{t+1}\right)^{-1}$

Kemudian, nilai $\hat{x}_{t+1}$ dan $P_{t+1}$ dicari dengan menggunakan nilai $\hat{x}_{\bar{t}+1}$ dan $P_{\bar{t}+1}$ yang diperoleh dari tahap prediksi. 


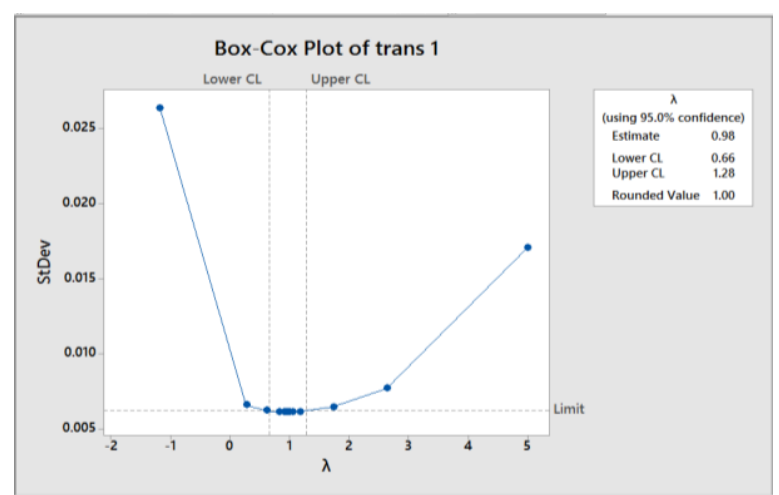

Gambar 1. Hasil Transformasi Box-Cox.

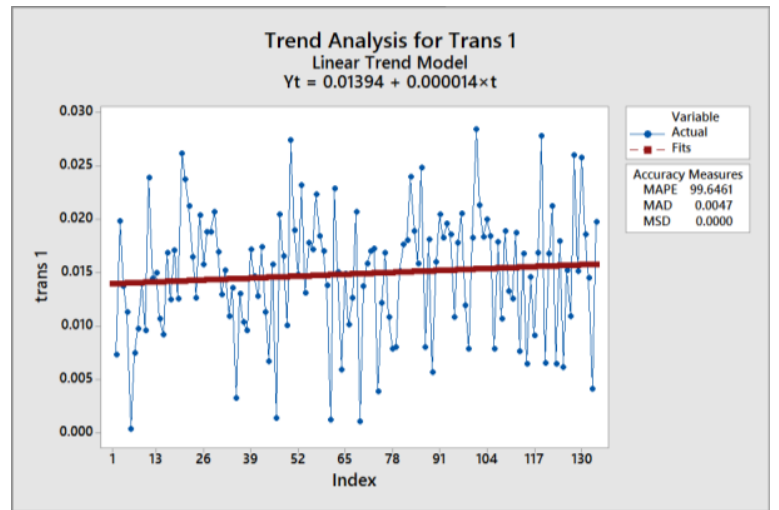

Gambar 2. Plot data Uji Stasioner Terhadap Mean.

$\hat{x}_{t+1}=\hat{x}_{\overline{t+1}}+P_{t+1} H_{t+1}^{T} R_{t+1}^{-1}\left(z_{t+1}-H_{t+1} \hat{x}_{\bar{t}+1}\right)$

$P_{t+1}=\left[\left(P_{\overline{t+1}}\right)^{-1}-H_{t+1}^{T} R_{t+1}^{-1} H_{t+1}\right]^{-1}$

Untuk simulasi estimasi parameter model ARIMA menggunakan Filter Kalman dilakukan dengan bantuan software Matlab. Iterasi yang dilakukan sebanyak jumlah data observasi yaitu 184. Nilai MAPE dan koefisien yang didapatkan dengan Filter Kalman sebesar 53,072\% .

Hasil simulasi perbandingan antara model ARIMA yang diestimasi menggunakan Filter Kalman dengan model ARIMA yang diestimasi dengan metode Least Square dapat dilihat pada Gambar 6.

Gambar 6 menunjukkan bahwa grafik model ARIMA yang diestimasi dengan Filter Kalman semakin mendekati data aktual daripada grafik ARIMA yang diestimasi dengan metode Least Square.

\section{Perbaikan Error Menggunakan Filter Kalman}

Model ARIMA yang sesuai kemudian akan diestimasi error dengan menggunakan Filter Kalman. Berikut ini penerapan Filter Kalman pada harga minyak mentah:

Persamaan model ARIMA padaharga minyak:

- Penerapan Filter Kalman dengan menggunakan polinomial derajat $1(n=2)$.

$y_{i}^{0}=a_{0, i}+a_{1, i} m_{i}$

Algoritma Filter Kalman yang digunakan dalam penelitian ini adalah sebagaiberikut:

Model sistem [5]:

$\left[\begin{array}{l}\alpha_{0, i} \\ a_{1, i}\end{array}\right]_{t+1}=\left[\begin{array}{ll}1 & 0 \\ 0 & 1\end{array}\right]\left[\begin{array}{l}\alpha_{0, i} \\ a_{1, i}\end{array}\right]_{t}+w_{t}$

Model pengukuran[5]:

$y_{i}^{0}=\left[\begin{array}{ll}1 & m_{i}\end{array}\right]\left[\begin{array}{l}\alpha_{0, i} \\ a_{1, i}\end{array}\right]_{t}$

Selanjutnya tahap inisialisasi, dengan menentukan nilai awal sebagaiberikut:

$R=10^{-4}, Q=10^{-3}$

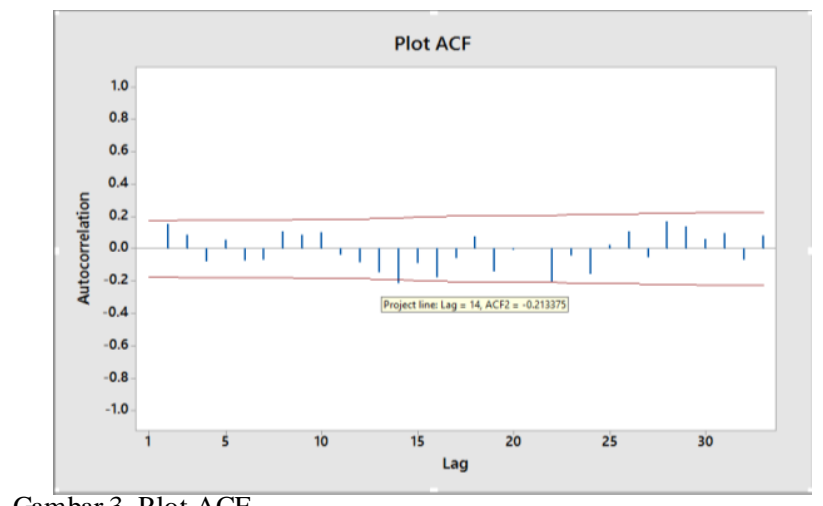

Gambar 3. Plot ACF.

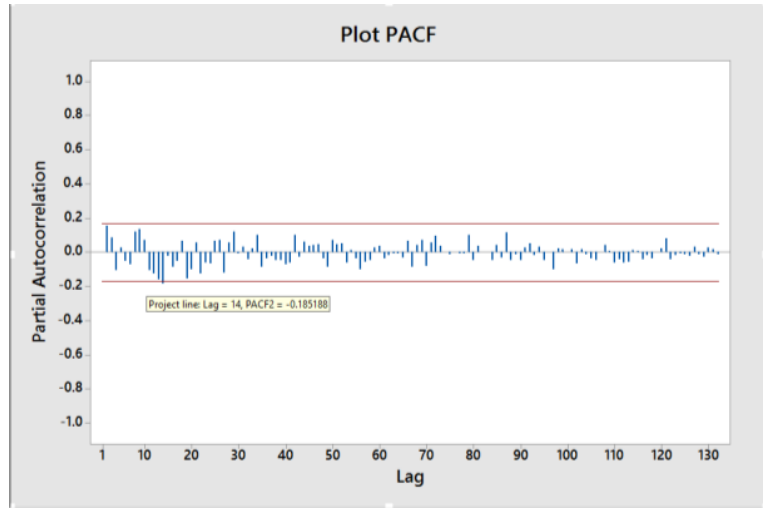

Gambar 4. Plot PACF.

$\hat{x}_{0}=\left[\begin{array}{l}-0,00173 \\ -0,00138\end{array}\right], P_{0}=\left[\begin{array}{ll}1 & 0 \\ 0 & 1\end{array}\right], Q_{t}=\left[\begin{array}{ll}1 & 0 \\ 0 & 1\end{array}\right] \cdot Q$

Tahap prediksi[5]:

$\hat{x}_{\bar{t}+1}=A_{t} \hat{x}_{t}$

$P_{\bar{t}+1}=A_{t} P_{t} A_{t}^{T}+G Q_{t} G^{T}$

Tahap koreksi[5]:

$K_{t+1}=P_{\bar{t}+1} H_{t+1}^{T}\left(H_{t+1} P_{\bar{t}+1} H_{t+1}^{T}+R_{t+1}\right)^{-1}$

Kemudian, nilai $\hat{x}_{t+1}$ dan $P_{t+1}$ dicari dengan menggunakan nilai $\hat{x}_{\bar{t}+1}$ dan $P_{\bar{t}+1}$ yang diperoleh dari tahap prediksi.

$\hat{x}_{t+1}=\hat{x}_{\bar{t}+1}+P_{t+1} H_{t+1}^{T} R_{t+1}^{-1}\left(z_{t+1}-H_{t+1} \hat{x}_{\bar{t}+1}\right)$

$P_{t+1}=\left[\left(P_{\bar{t}+1}\right)^{-1}-H_{t+1}^{T} R_{t+1}^{-1} H_{t+1}\right]^{-1}$

Untuk simulasi estimasi parameter model ARIMA menggunakan Filter Kalman dilakukan dengan bantuan software Matlab. Iterasi yang dilakukan sebanyak jumlah data observasi yaitu 184. Nilai MAPE perbaikan error yang didapatkan dengan Filter Kalman dan ARIMA sebesar $10,5197 \%$.

Dengan demikian model untuk prediksi harga komoditas minyak mentah dengan perbaikan error Filter Kalman dapat dituliskan sebagaiberikut:

$X_{t}=0,986 X_{t-14}+0,884 \alpha_{t-14}+0,0024644+0,9554 m_{1}$ atau dapat diuliskan dalam persamaan $Y_{t}$ sebagaiberikut:

$$
\begin{array}{r}
Y_{t}=\left(0,986281\left(Y_{t-14}\right)^{3 / 2}+\alpha_{t}+0,884142 \alpha_{t-14}\right. \\
\left.+0,0024644+0,9554 m_{i}\right)^{2 / 3}
\end{array}
$$

Hasil simulasi perbandingan antara model ARIMA yang diestimasi menggunakan Filter Kalman dengan model ARIMA yang diestimasi dengan metode Least Square dapat dilihat pada Gambar 7 yang menunjukkan bahwa grafik model ARIMA yang diestimasi dengan Filter Kalman mendekati data aktual daripada grafik ARIMA yang diestimasi dengan metode Least Square. 


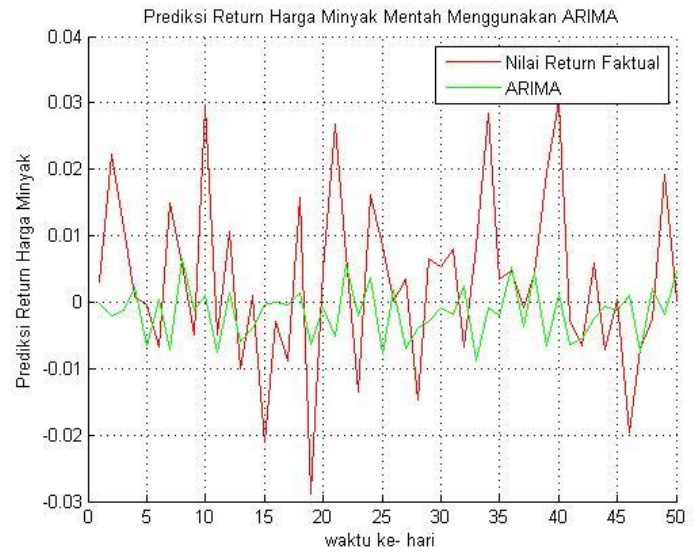

Gambar 5. Hasil Simulasi Perbandingan Nilai Faktual dengan ARIMA.

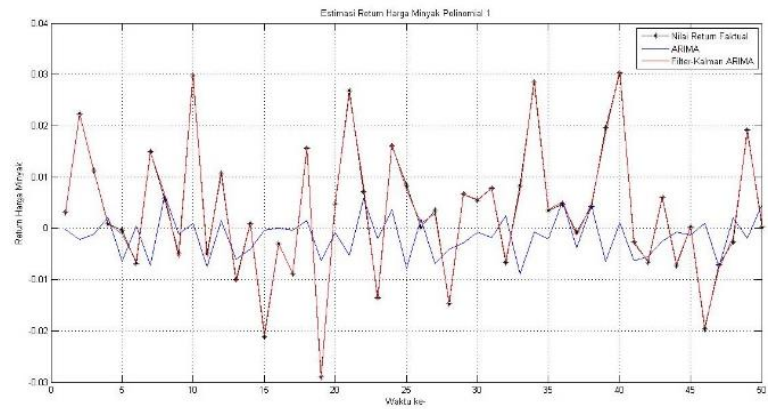

Gambar 7. Hasil Simulasi Perbandingan ARIMA, ARIMA-Filter Kalman Perbaikan Error $(n=2)$, dan Faktual.

Penerapan Filter Kalman dengan menggunakan polinomial derajat $2(n=3)$.

$y_{i}^{0}=a_{0, i}+a_{1, i} m_{i}+a_{2, i} m_{i}^{2}$

Algoritma Filter Kalman yang digunakan dalam penelitian ini adalah sebagaiberikut:

Model sistem[5]:

$\left[\begin{array}{l}\alpha_{0, i} \\ a_{1, i} \\ a_{2, i}\end{array}\right]_{t+1}=\left[\begin{array}{lll}1 & 0 & 0 \\ 0 & 1 & 0 \\ 0 & 0 & 1\end{array}\right]\left[\begin{array}{l}\alpha_{0, i} \\ a_{1, i} \\ a_{2, i}\end{array}\right]_{t}$

Model pengukuran[5]:

$y_{i}{ }^{0}=\left[\begin{array}{lll}1 & m_{i} & m_{i}{ }^{2}\end{array}\right]\left[\begin{array}{l}\alpha_{0, i} \\ a_{1, i} \\ a_{2, i}\end{array}\right]_{t}$

Selanjutnya tahap inisialis asi, dengan menentukan nilai awal sebagaiberikut:

$R=10^{-7}, Q=10^{-6}$

$\hat{x}_{0}=\left[\begin{array}{l}-0,00173 \\ -0,00138 \\ -0,00162\end{array}\right], P_{0}=\left[\begin{array}{lll}1 & 0 & 0 \\ 0 & 1 & 0 \\ 0 & 0 & 1\end{array}\right]$

Tahap prediksi[5]:

$\hat{x}_{\bar{t}+1}=A_{t} \hat{x}_{t}$

$P_{\bar{t}+1}=A_{t} P_{t} A_{t}^{T}+G Q_{t} G^{T}$

Tahap koreksi[5]:

$K_{t+1}=P_{\bar{t}+1} H_{t+1}^{T}\left(H_{t+1} P_{\bar{t}+1} H_{t+1}^{T}+R_{t+1}\right)^{-1}$

Kemudian, nilai $\hat{x}_{t+1}$ dan $P_{t+1}$ dicari dengan menggunakan nilai $\hat{x}_{\bar{t}+1}$ dan $P_{\bar{t}+1}$ yang diperoleh dari tahap prediksi.

$\hat{x}_{t+1}=\hat{x}_{\bar{t}+1}+P_{t+1} H_{t+1}^{T} R_{t+1}^{-1}\left(z_{t+1}-H_{t+1} \hat{x}_{\bar{t}+1}\right)$

$P_{t+1}=\left[\left(P_{\bar{t}+1}\right)^{-1}-H_{t+1}^{T} R_{t+1}^{-1} H_{t+1}\right]^{-1}$

Untuk simulasi estimasi parameter model ARIMA menggunakan Filter Kalman dilakukan dengan bantuan software Matlab. Iterasi yang dilakukan sebanyak jumlah data observasi yaitu 184. Nilai MAPE perbaikan error yang

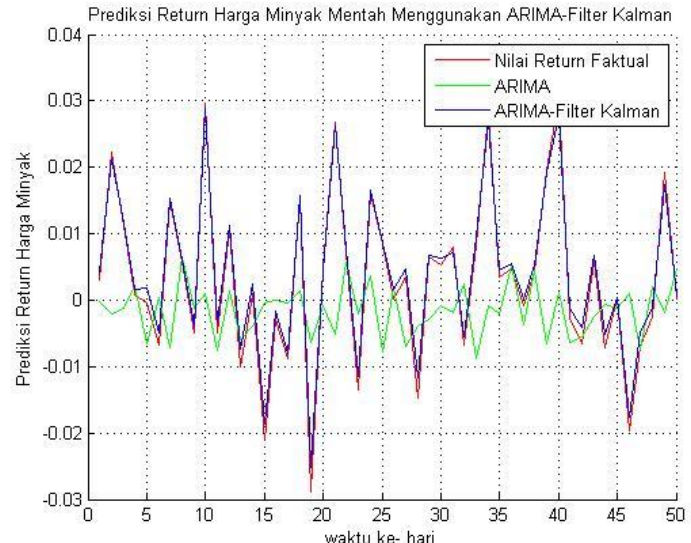

Gambar 6. Grafik Perbandingan ARIMA, ARIMA-Filter Kalman, dan Faktual.

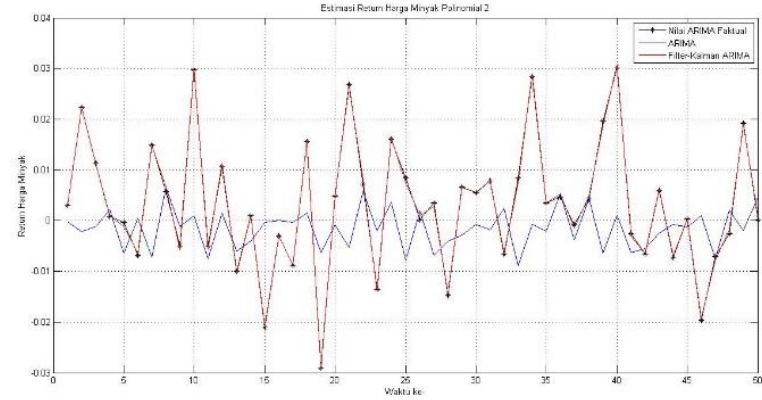

Gambar 8. Hasil Simulasi Perbandingan ARIMA, ARIMA-Filter Kalman Perbaikan Error $(n=3)$, dan Faktual.

didapatkan dengan Filter Kalman dan ARIMA sebesar $3,6947 \%$.

Dengan demikian model untuk prediksi harga komoditas minyak mentah dengan perbaikan error Filter Kalman dapat dituliskan sebagaiberikut:

$\begin{aligned} X_{t}=0,986 X_{t-14} & +0,884 \alpha_{t-14}+0,0023659+0,9522 m_{1} \\ & +0,45283 m_{1}^{2}\end{aligned}$

atau dapat diuliskan dalam persamaan $Y_{t}$ sebagaiberikut:

$$
\begin{aligned}
Y_{t}=(0,986281 & \left(Y_{t-14}\right)^{3 / 2}+0,884142 \alpha_{t-14} \\
& +0,0023659+0,95222 m_{i} \\
& \left.+0,452834 m_{i}{ }^{2}\right)^{2 / 3}
\end{aligned}
$$

Hasil simulasi perbandingan antara model ARIMA yang diestimasi menggunakan Filter Kalman dengan model ARIMA yang diestimasi dengan metode Least Square dapat dilihat pada Gambar 8 yang menunjukkan bahwa grafik model ARIMA yang diestimasi dengan Filter Kalman mendekati data aktual daripada grafik ARIMA yang diestimasi dengan metode Least Square.

\section{KESIMPULAN}

1. Model ARIMA terbaik yang didapatkan adalah ARIMA ([14],0, [14]) dengan MAPE 217,554\% dan dirumuskan secara matematis sebagaiberikut:

$$
Y_{t}=\left(0,986281\left(Y_{t-14}\right)^{3 / 2}+\alpha_{t}+0,884142 \alpha_{t-14}\right)^{\frac{2}{3}}
$$

2. Dengan Metode Filter Kalman untuk mengestimasi parameter pada model ARIMA menghasilkan nilai MAPE sebesar 53,072\%. Sedangkan pada perbaikan error untuk polinomial derajat pertama dan kedua dengan nilai awal yang sama untuk setiap $Q$ dan $R$ yang diambil 
$\left(Q=10^{-6}\right.$ dan $\left.R=10^{-7}\right)$, nilai MAPE perbaikan error polinomial derajat kedua lebih baik daripada derajat pertama dengan nilai 3,6947\% untuk derajat kedua dan $10,5197 \%$ untuk derajat pertama.

3. Prediksi return harga komoditas minyak mentah untuk50 selanjutnya adalah pada kisaran $-\$ 0.029256$ hingga $\$ 0.030855$.

\section{DAFTAR PUSTAKA}

Available: www.eia.doe.gov. [Accessed: 20-Jul-2003].

[2] R. F. Engle and C. W. . Granger, "Cointegration and Error Correction: Representation, Estimation, and Testing," Econometrica, vol. 55, no. 2,pp.251-276, 1987.

[3] T. Bollerslev, "Generalized Autoregressive Conditional Heteroscedasticity," J. Econom., vol. 31, pp. 307-327, 1986.

[4] M. Pamungkas, "Estimasi Parameter Model ARIMA Menggunakan Kalman Filter Untuk Peramalan Permintaan Darah,”Surabaya, 2016.

[5] P. Febritasari, "Estimasi Inflasi Wilayah Kerja KpwBI Malang Menggunakan Arima-Kalman Filter Dan Var-Kalman Filter," Surabaya, 2016. 